\title{
ADOLESCENTES E REDES SOCIAIS: VIOLÊNCIA DE GÊNERO, SEXTING E CYBERBULLYING NO FILME FERRUGEM
}

\author{
ADOLESCENTS AND SOCIAL NETWORKS: GENDER VIOLENCE, SEXTING \\ AND CYBERBULLYING IN THE MOVIE FERRUGEM
}

\section{SILVIA RENATA LORDELLO}

LARA SOUZA

\section{LETÍCIA DE AMORIM MOTA COELHO}

Universidade de Brasilia (UnB), Brasilia/DF, Brasil
RESUMO: Neste artigo, buscou-se apresentar reflexões teóricas, à luz da perspectiva sistêmica, sobre os conceitos da violência de gênero, do sexting e do cyberbullying retratados no filme brasileiro "Ferrugem", lançado em 2018. 0 filme aborda uma temática presente na realidade da juventude, destacando riscos na utilização das redes sociais e os impactos da exposição não autorizada de imagens íntimas. Foram elaboradas cinco seções temáticas a partir da narrativa apresentada, com 0 intuito de explanar conceitos e analisar os fenômenos de maneira dialógica: (a) a subjetivação dos adolescentes na era digital; (b) os reflexos do sexismo nas relações entre os jovens; (c) o desenvolvimento de processos identitários articulados às dinâmicas familiares; (d) a corresponsabilização do ofensor sexual adolescente; (e) repercussões e implicações para as intervenções em diferentes campos. 0 filme "Ferrugem" expõe demandas complexas e nos convoca a agir para intervir nesses contextos, descortinando e visibilizando as práticas de sexting e cyberbullying.

PALAVRAS-ChaVE: Sexting; Cyberbullying; Adolescência; Recursos Terapêuticos, Intervenções.
ABSTRACT: In this article, we sought to present systemic reflections on the concepts of gender violence, sexting and cyberbullying portrayed in Brazilian movie "'Ferrugem", released in 2018. The film addresses a theme with strong presence in youth reality, highlighting the risks in use of social networks and the impacts of unauthorized exposure of intimate images. Five thematic sections were elaborated, based on the narrative presented, to explain concepts and to analyze the phenomena in a dialogical way: (a) the subjectivation of adolescents in a digital society; (b) the reflexes of sexism in the relations between young adults; (c) the development of identity processes articulated to family dynamic; (d) the co-responsibility of the adolescent sexual offender; e) repercussions and implications for interventions in different areas. The movie exposes complex demands and calls us to act to intervene in these contexts, revealing and making visible the practices of sexting and cyberbullying.

KEYWORDS: Sexting; Cyberbullying; Adolescence; Therapeutic Resources; Interventions.
Recebido em: 12/11/2018 Aprovado em: 30/09/2019

\section{RELACIONAMENTOS AFETIVOS E REDES SOCIAIS}

Os relacionamentos afetivos são perpassados por diferentes fatores socioculturais, que impactam a forma como as pessoas interagem, especialmente em relações românticas. Dentre esses fatores, pode-se observar o crescimento da mediação tecnológica das relações, que podem ser iniciadas e mantidas por meio de recursos eletrônicos (Korenis \& Billick, 2014; Ybarra \& Mitchell, 2014). Os relacionamentos sexuais também são impactados pela tecnologia e, de acordo com estudos recentes, 
a maioria dos jovens adultos já manteve relações sexuais virtuais pelo menos uma vez (Drouin, Ross, \& Tobin, 2015; Ross, Drouin, \& Coupe, 2019). A partir dessas novas relações, surgiu o termo sexting, que pode ser definido como mensagem virtual de conteúdo sexual, podendo ou não conter imagens (Albury, Crawford, Byron, \& Mathews, 2013). Essa forma de comunicação também pode ocorrer por meio de vídeos, telefonemas ou mensagens de voz (Drouin et al., 2015).

Embora o sexting seja comumente considerado um fator de risco a prio$r i$, o fenômeno é indicado como parte natural das relações amorosas por muitos participantes em estudos da área (Drouin, Vogel, Surbey, \& Stills, 2013; Lee \& Crofts, 2015; Mitchell, Finkelhor, Jones, \& Wolak, 2012). Observa-se que o risco atrelado às mensagens de conteúdo sexual está mais relacionado a outros fenômenos, como o cyberbullying e a violência de gênero, que serão discutidos mais adiante neste trabalho. Outro fator que se caracteriza como risco atrelado ao sexting é o risco de exposição das mensagens íntimas, que pode gerar diversas consequências negativas para a vítima exposta. Juvonen e Gross (2008) conceituam o cyberbullying como o uso da tecnologia como forma de praticar assédio, ameaças e ações agressivas e violentas aos pares que contenham uma relação desigual de poder. Dentre as formas de expressões mais comuns do cyberbullying estão o compartilhamento e a divulgação de fotos e vídeos sem autorização, além de manipulação de imagens sem o consentimento da pessoa (Wendt \& Lisboa, 2013).

De acordo com a Organização Não Governamental SaferNet (2019), a exposição de imagens íntimas foi a violação para a qual os brasileiros mais buscaram auxílio em 2018, contabilizando
669 atendimentos na ONG, que é especializada em auxílio a crimes virtuais e tem parceria governamental. Este número foi significativamente maior que a quantidade de atendimentos ao segundo e ao terceiro tipos de crime que mais geram pedidos de auxílio, cyberbullying (407) e fraude (242), respectivamente. É importante destacar que o número de atendimentos a casos de exposição de imagens íntimas em 2018 foi superior ao dobro dos atendimentos realizados em 2017, que haviam atingido o número de 289 ( $\mathrm{Sa}$ ferNet, 2018). Esse crescimento chama atenção para uma possível mudança no macrossistema em relação ao fenômeno, visto que mais vítimas fizeram denúncia e souberam os órgãos que poderiam oferecer auxílio.

Outro aspecto a ser ressaltado nos dados apresentados pela SaferNet (2019) é o gênero das vítimas de exposição de imagens íntimas. Em 65,8\% dos casos atendidos pela ONG em 2018, a vítima era mulher. Esse padrão também foi observado em 2017, em que $70,6 \%$ das vítimas atendidas eram do sexo feminino. Tais dados indicam que há diferença de gênero entre as vítimas de exposição de sexting e funcionam como um alerta para a necessidade de proteção às mulheres e de investigação acerca dos fatores que geram essa desigualdade. Nesta direção, observa-se que $o$ assunto tem gerado mais discussões, sendo alvo de campanhas governamentais e de comunicações sociais.

Os impactos das mudanças sociais acerca da exposição de mensagens podem ser observados nas leis recentemente criadas com intuito de proteger as vítimas desses crimes. No Brasil, a legislação sobre a exposição do sexting obteve avanços significativos no ano de 2018 com a inclusão da violação de privacidade e do combate expresso às produções e às divulgações inapropriadas 
de imagens íntimas na Lei 11.340/2006 - conhecida como Lei Maria da Penha. Ademais, a divulgação inapropriada de cenas de sexo também foi tipificada pela Lei 13.718/18, classificando a exposição de sexting como crime. Antes dessas leis, a exposição de mensagens poderia apenas ser enquadrada em outras leis mais amplas, como difamação e injúria (Art.139 e 140) e a Lei $12.737 / 2012$, que trata de crimes informáticos. A recente elaboração de leis específicas para casos de exposição de sexting evidencia as repercussões do fenômeno no macrossistema brasileiro.

Os efeitos dessa mudança macro também podem ser observados em outros aspectos além das modificações legais. Conforme citado, o sexting e a exposição de mensagens têm sido debatidos em diferentes formatos. Nos últimos anos, foram elaboradas campanhas institucionais e governamentais acerca da produção de imagens de conteúdo sexual e intervenções de prevenção à exposição de conteúdo íntimo. O debate também tem sido promovido na mídia, como em novelas televisivas e filmes nacionais. O crescimento dessa discussão demonstra uma nova perspectiva social em relação ao assunto e indica como recursos midiáticos, sejam campanhas tradicionais ou conteúdos televisivos, impactam as visões da sociedade sobre $\mathrm{o}$ assunto.

Considerando a importância dos recursos citados, o objetivo deste artigo é apresentar reflexões teóricas sobre os conceitos da violência de gênero, do sexting e do cyberbullying retratados no filme brasileiro "Ferrugem", lançado em 2018 e premiado no Festival de Cinema de Gramado do mesmo ano. Dirigido pelo cineasta Ary Muritiba, o filme aborda os riscos na utilização das redes sociais e promove a discussão sobre os impactos da exposição de imagens íntimas não autorizadas. $\mathrm{O}$ filme trata de uma temática muito presente na realidade da juventude atual e entende-se como oportunidade ímpar para explanar conceitos técnicos e ilustrá-los, propondo uma forma interdisciplinar de análise do fenômeno. De qualidade cinematográfica indiscutível, não se pretende abordar neste artigo os elementos da linguagem artística. Reconhece-se, entretanto, que imagens, pausas e silêncios foram recursos intencionalmente empregados no caráter reflexivo que o filme visa retratar.

De maneira sucinta, o filme inicia destacando Tati e Renet, que são adolescentes e estão em uma excursão de escola. Em um momento noturno Tati e Renet se afastam do grupo e, quando estão iniciando um clima romântico, ela nota a falta do celular. Todos procuram e não encontram. A cena seguinte é sua chegada à escola, notando olhares, quando é alertada de que uma imagem de cena íntima com seu ex-namorado foi divulgada sem a sua autorização. Em seguida, passa a presenciar as mais impactantes consequências deste fato, cometendo, inclusive, suicídio, após vários episódios violentos sofridos por ela. A segunda parte do filme revela a perspectiva, os dilemas e os sentimentos dos que, de alguma forma, envolveram-se na situação, seus dilemas e sentimentos. Neste artigo, faremos alguns recortes de cenas e proporemos uma reflexão teórica a partir dos conceitos nelas contidos.

\section{NASCENDO NUMA SOCIEDADE TECNOLÓGICA}

Nos atuais debates, é comum o questionamento sobre a dependência que os adolescentes desenvolvem em relação às tecnologias. Aqui se pretende incluir uma análise sócio-histórica, pela qual se defende que o adolescente 
de hoje não desenvolveu o intenso uso da internet como patologia, mas como consequência de uma subjetivação em uma sociedade na qual a tecnologia ocupa posição de destaque. A velocidade das atualizações e a necessidade do uso de tecnologia são sentidas por todos, adolescentes ou não. $\mathrm{O}$ filme evidencia essa tendência em sua primeira cena, na qual adolescentes estão numa visita escolar a um aquário e veem as espécies aquáticas pelas lentes de suas câmeras, retratando-as na forma de selfies. O professor faz uma advertência sobre isso, mas não os convence a abandonar seus celulares para tal contemplação. Alguns autores apontam que o principal motivo das redes sociais serem consideradas como fundamental na vida dos jovens é que elas modificaram as formas de comunicação e interação e o jovem entende o espaço virtual com a mesma legitimidade que o espaço real (Araújo \& Figueiredo, 2017). Além disso, a utilização das mídias sociais por esse público atua como instrumento de mediação social, de estabelecimento de vínculos e de possibilidades de novas configurações de relacionamento (Schiavi \& Lorentz, 2016).

Outro aspecto relevante a ser considerado é que o conceito de adolescência seja compreendido no plural, ou seja, são adolescências. O filme apresenta a vivência de jovens de classe média, ou média alta, de uma grande capital do país. Não se pode generalizar que a adolescência retratada no filme seja a de todos os brasileiros. Cerqueira-Santos, Melo Neto e Koller (2014) afirmam que a adolescência é uma construção social recente. Até pouco tempo, não se consideravam especificidades desse período do desenvolvimento e estudos atuais apontam para uma perspectiva contextual, na qual se reconhecem diferentes adolescências, considerando as relações entre indivíduos e seus contextos (Lerner, 2018; Senna \& Dessen, 2012). Portanto, a adolescência como construção social será articulada ao contexto. Um adolescente de baixa renda, que trabalhe e tenha acesso limitado à educação, significará este período de outra forma. O que se observa é que o uso da internet é uma particularidade comum entre as diferentes adolescências, embora as formas de uso ocorram de acordo com a oportunidade de acesso.

O filme revela o quanto as relações dos adultos são permeadas pelo despreparo e pela visão universalista de adolescência, reflexo de uma cultura que se indispõe a ouvir e aprender com o próprio jovem que está se desenvolvendo. Essa é uma advertência necessária ao se falar em adolescências, pois é recorrente o perigo da produção de estereótipos. Cerqueira-Santos, Melo Neto e Koller (2014) problematizam os efeitos de um entendimento normativo que considere a adolescência uma fase estanque, naturalizada e determinista, que limita entendimentos e desconsidera condições sociais nas quais estão inseridos. Autores que veem a adolescência por outra perspectiva analisam a importância da vivência desse período como um momento essencial de transformação, transposição e autoafirmação não só dos adolescentes que o vivenciam, como dos que com eles convivem (Lerner, 2018).

\section{AS SUTILEZAS DA VIOLÊNCIA DE GÊNERO}

A forma de vivenciar a adolescência também é influenciada pelas práticas culturais vigentes no contexto do adolescente, o que é retratado no filme em diversas situações de sexismo. Swim e 
Hayes (2011) definem sexismo como comportamentos ou crenças que mantenham a desigualdade entre homens e mulheres, reproduzindo avaliações de indivíduos com base em seu gênero. Este padrão é naturalizado nas relações entre os jovens do filme e pode ser observado inicialmente por meio da crítica ao ex-namorado da protagonista Tati. A suposta traição da qual foi vítima é minimizada pelos amigos do gênero masculino, que justificam que seu ex-companheiro não tem culpa pelo fato de ser procurado por tantas meninas. Essas mesmas justificativas para os comportamentos masculinos são sutilmente apresentadas ao longo de todo o filme.

Após a exposição do vídeo sem autorização, quando Tati perde o celular, os colegas fazem inexpressiva crítica ao ex-namorado que estava na cena viralizada e promovem danos irreparáveis à adolescente, que é julgada, ironizada e pejorativamente tratada por todos na escola que viram o vídeo. Piadas como as direcionadas à personagem ao longo do filme são amplamente difundidas na cultura e, de modo geral, são relativas à vulgaridade, desqualificação moral e humilhação da mulher. $\mathrm{O}$ afastamento das amigas, a crítica dos rapazes à companhia de uma garota que foi flagrada em uma cena de sexo, o repúdio dos colegas, o silêncio do professor diante das piadas sexistas e até mesmo o olhar irônico e insinuante de um funcionário da escola são outros detalhes do filme que podem ser caracterizados como slut-shaming, que é uma forma de ridicularização da mulher e se mostra presente em todo o enredo.

Gong e Hoffman (2012) definem slut-shaming como um bullying de caráter sexual direcionado a mulheres e afirmam que essa forma de violência tem o intuito de degradar a mulher criticada. O slut-shaming está presente em diversos espaços da personagem, inclusive na sala de aula durante uma apresentação de trabalho, em que os colegas fazem associações humilhantes que dizem respeito à suposta vulgaridade de Tati. Esses exemplos corroboram a literatura internacional, cujos estudos apontam que as consequências do vazamento de imagens íntimas trazem repercussões mais graves às mulheres (Mejía-Soto, 2014; Walker, Sanci \& Temple-Smith, 2013). De acordo com Hasinoff (2017), as meninas que têm sua intimidade exposta são tão responsabilizadas pela exposição quanto a pessoa que de fato divulgou o sexting e enfrentam, além da violação de privacidade, a vitimização por slut-shaming.

O bullying de conteúdo sexual também pode provocar impactos negativos na saúde mental (Grov, Gillespie, Royce, \& Lever, 2011). Bannink e cols. (2014) realizaram um estudo acerca da relação entre bullying e cyberbullying com a saúde mental de adolescentes, analisando as diferenças de gênero. Os resultados evidenciaram que tanto bullying quanto cyberbullying estavam associados a problemas de saúde mental - como desenvolvimento de ansiedade e depressão - entre as meninas, enquanto entre os meninos não foi observada tal relação. A ideação suicida também foi mais frequente entre meninas. Essa relação é observada no filme quando Tati decide cometer suicídio. Diante das humilhações e da falta de suporte social, ela acredita que não tem outra saída além de provocar autoextermínio e decide fazê-lo na escola, diante de uma câmera de segurança, o que sugere uma possível denúncia do contexto adoecedor que a escola passou a representar. 
É importante destacar que, mesmo após o suicídio da adolescente, os colegas continuam desqualificando e culpabilizando a jovem. O primo de Renet é um exemplo: ao quebrar seu celular para se livrar das provas, ele atribui à Tati a culpa por envolvê-lo em seus problemas, por um suposto desequilíbrio dela. A literatura destaca que nestes discursos de culpabilização das mulheres vítimas de violências é recorrente o desvio de responsabilidade do verdadeiro agressor, contribuindo para a manutenção de silenciamentos, de submissões diante dos abusos sofridos e para a naturalização de papéis estereotipados de gênero (Hasinoff, 2017; Narvaz \& Koller, 2006). Além disso, há uma tendência social de desqualificação dos processos de adoecimento psíquico das vítimas de violências, criando barreiras de acesso aos serviços de saúde especializados nos atendimentos às mulheres (Souza \& Cintra, 2018). Com relação ao suicídio, esse paradigma de responsabilização da vítima torna-se semelhante na medida em que prevalece o pensamento linear, causal e individualizante do comportamento suicida em detrimento de uma perspectiva sócio- histórica, multifatorial e com condicionantes biopsicossociais. É perceptível que o diálogo entre Renet e seu primo sugere uma visão descontextualizada e estigmatizante do suicídio de Tati, dificultando ações de manejo dos fatores de riscos da situação em que os adolescentes foram expostos.

A falta de intervenção de um adulto também retrata os dados internacionais que apontam a escola como um lugar no qual o debate sobre questões relativas ao cyberbullying e outros mecanismos se mostra ausente (Agatston, Kowalski, \& Limber, 2007). O filme retrata o rápido pro- cesso de Tati sem que nenhuma intervenção seja abordada, o que também remete à ideia de que a falta de posicionamento diante das provocações percebidas e ignoradas nos ambientes institucionais e nas famílias represente uma questão que precisa ser problematizada.

\section{SILENCIAMENTOS E COMUNICAÇÃO FAMILIAR}

Diante da situação conflituosa que vive, Tati percebe a fragilidade de sua rede de apoio, uma vez que se percebe sozinha e sem suporte social para compartilhar seu sofrimento. Não sabe mais que desculpas apresentar aos pais para suas faltasà escola, repara um aviso da coordenação sobre uma reunião de pais e, aparentemente, interpreta que seu caso seria exposto pela equipe pedagógica. A literatura aponta que um envolvimento integrado e positivo entre família e escola pode contribuir para um melhor desenvolvimento nos níveis cognitivos, afetivos, sociais e de personalidade dos alunos (Polonia \& Dessen, 2005). Nesse sentido, faz-se necessário reconhecer como teria sido importante uma ação complementar entre os contextos familiar e escolar da personagem, visto que poderiam ter viabilizado recursos psicossociais para o enfrentamento da violência vivenciada pela adolescente. Essa ação integrada e corresponsável poderia ter possibilitado um desfecho alternativo para a história do filme.

Nota-se que o diálogo entre jovens e adultos no filme é quase inexistente, o que pode significar um retrato da realidade. O filme denuncia uma cultura que não se dispõe a ouvir o adolescente e retrata poucos personagens que mostram essa abertura. De forma mais específica, apenas a 
mãe do personagem Renet consegue mostrar interesse genuíno por seu mundo e enfrenta as barreiras para ouvir o que ele tem a dizer. Entretanto, é visto que, ao chegar na casa de praia após um ano sem encontrar o filho, ela tenta se comunicar com ele de uma maneira impositiva e autoritária, o que reflete em alguns comportamentos de esquiva do jovem. Apenas após a mãe ter demonstrado uma postura de abertura ao diálogo com o adolescente, foi possível observar também um comportamento semelhante de Renet, sobretudo com relação à sua responsabilização frente aos pais de Tati sobre o seu ato de divulgar o vídeo.

É importante que o adolescente desenvolva uma identidade própria, que permita que ele se distancie dos modelos parentais internalizados até então. O exercício de se opor às ideias dos pais e outros familiares é uma forma de começar a construir sua identidade. Isso causa estranhamento nos mais próximos, que julgam haver um distanciamento afetivo, mas não é isso que ocorre. $\mathrm{O}$ adolescente leva em consideração o que os adultos que lhe são referências pensam e como agem, porém, a verdadeira construção de um eu exige que ele desenvolva suas próprias ideias. É inevitável que a família vivencie adaptações necessárias para acolher esses processos (Wagner, Carpenedo, Melo, \& Silveira, 2005). Carter e McGoldrick (2001) afirmam que uma habilidade parental importante nessa fase é negociar limites sem abrir mão deles. $\mathrm{O}$ adolescente requer esse ajuste da família à sua nova forma de pensar, que inclui hipotetização de situações e esclarecimentos sobre decisões. Estratégias de comunicação são úteis para conciliar os movimentos desejáveis de autonomia com a preservação do espaço pessoal dos adolescentes (Wagner, Carpenedo, Melo, \& Silveira, 2005).

Imersos em um cenário de muita solidão comunicativa, os adolescentes vivenciam um trauma com a perda da colega. Nota-se que o sistema familiar e a escola ficam também imobilizados pela situação e não conseguem promover um diálogo sobre a morte de Tati. É notório o quanto o sexting, o suicídio e outros temas representam um grande desafio na comunicação com os adolescentes. E o porquê disso não se pode responder de forma unicausal. Vários estudos apontam a importância de os familiares e profissionais da escola agirem de forma protetiva ao suicídio de adolescentes, compreendendo a dinâmica e os fatores relativos ao fenômeno e desenvolverem ações preventivas (Braga \& Dell'Aglio, 2013; Kokkevi, Rotsika, Arapaki \& Richardson, 2010). Entretanto, mesmo que tais necessidades sejam reconhecidas, ainda são raros estudos que se mostrem propositivos neste campo, e que contribuam para o preparo de familiares e profissionais (Cardoso, Falcke, \& Mosmann, 2019).

Além disso, também é comum a disseminação de informações equivocadas relacionadas ao suicídio, distanciando os profissionais e a sociedade de uma prática preventiva e responsável (Braga \& Dell'Aglio, 2013). Para que não seja assumido um tom de culpabilização, que jamais seria a proposta deste texto, é necessário problematizar as construções sócio-históricas em torno de um fenômeno novo como a extensão da tecnologia no campo dos relacionamentos. Intervenções ainda precisam ser pensadas na área, pois pais e escolas são tomados por uma incerteza de que suas ações serão efetivas, por um espectro multifatorial, como o receio de agravar os quadros, reedição 
de vivências pessoais negativas com o tema, desconhecimento de como lidar com um fenômeno crescente, mas absolutamente inédito em seu repertório, entre tantas outras variáveis para a adoção de posturas que podem ser erroneamente interpretadas como indiferença.

Caberia aqui uma problematização que pode romper a linearidade de um julgamento indesejável: a atitude de não abertura à conversação dificultou a construção de espaços de esclarecimentos e de manifestações de sofrimentos nas interações de Tati e de Renet na família e na escola? Consideraríamos fácil o convite a este diálogo? O fato de a família e de a escola proporem debater o tema seria suficiente para uma aceitação dessa proposta pelos adolescentes? Deste modo, a situação ilustra o desafio do diálogo que, embora se reconheça necessário, nem sempre é exequível. Não se nega aqui a necessidade de capacitação da comunidade escolar para lidar com as questões de saúde mental dos adolescentes, e a relevância de construir ações dialógicas entre os dois sistemas. Porém, é preciso lembrar que, mesmo que esse recurso seja inquestionável, o desafio de interpretar e manejar os fatores de risco ao suicídio são construídos em um processo baseado em relações de respeito, confiança, afeto e abertura, totalmente vinculados a uma conjuntura macrossistêmica que precisa ser considerada em todo o percurso (Abreu, Lima, Kohlrausch. \& Soares, 2010; Pratta \& Santos, 2007).

\section{O OFENSOR SEXUAL ADOLESCENTE: DO IMPULSO À RESPONSABILIZAÇÃO}

A segunda parte do filme se dedica a apresentar os efeitos da morte da jovem sobre o adolescente responsável pelo vazamento das imagens íntimas. O professor e também pai do jovem o leva junto com seu primo e irmã para uma praia e lá o adolescente revive intensamente seus últimos momentos com Tati, seja ouvindo sua saudação na caixa postal, ou relendo suas últimas conversas na rede social. Sua mãe, grávida do segundo casamento, chega à praia e vê seu filho sofrendo e, após um sumiço proposital, revela sobre a necessidade de ele depor e de falar o que sabe sobre o fato, assumindo parte no ocorrido. A mãe discute com o pai sobre sua ação superprotetora de minimizar a responsabilidade do filho na situação e encoraja Renet a voltar com ela para a cidade a fim de dar o depoimento. Ao voltar com sua mãe, ele pede que ela estacione na casa da família de Tati e devolve à mãe dela o celular da filha, assumindo a culpa pela exposição do vídeo. O adolescente recebe um tapa e uma recusa das desculpas. Tais cenas trazem uma importante reflexão no cenário da prática do sexting por adolescentes, evidenciando a importância dos contextos em responsabilizar o adolescente ofensor.

A literatura mostra que a maior parte dos jovens já recebeu mensagens e imagens íntimas e, em muitos casos, as imagens foram repassadas ou enviadas de forma não autorizada (Drouin et al., 2013). A narrativa revela um caso de repasse de imagens, realizado de forma impulsiva. A divulgação parece ocorrer por um empoderamento masculino de ter propriedade sobre um conteúdo dessa gravidade e ganhar status ao enviar, sendo reforçado em sua virilidade ao propagar a objetificação feminina. Essa relação de empoderamento é corroborada nos estudos acerca do fenômeno, os quais revelam que os meninos sofrem pressão, principalmente por parte de outros meninos, para divulgar o sexting que 
recebem e são vistos como másculos quando isso ocorre (Walker, Sanci, \& Temple-Smith, 2013). É importante destacar que o filme não trata de um caso de pornografia de vingança, pois não havia um objetivo de vingança ou ciúmes, porém, evidencia o enaltecimento da virilidade, que faz parte do cenário do machismo estrutural.

É interessante notar o quanto as cenas demonstram um arrependimento de Renet, mas que não foi capaz de minimizar as consequências desastrosas do ato impulsivo e naturalizado na cultura. Enfraquecer esse movimento de objetificação do corpo feminino com uma reflexão de gênero abrangente discutida nas escolas, poderia ser um trabalho interventivo e de promoção de saúde desejável. Essa intervenção pouparia muito sofrimento às vítimas e evitaria relacionamentos abusivos tardiamente identificados pelos envolvidos. A escassez de estudos sobre intervenções de responsabilização dos ofensores permite mostrar que o filme encerra sua mensagem final com uma tarefa para o público e para os pesquisadores: sem paternalismo ou minimizações de responsabilidade.

\section{IMPLICAÇÕES PARA AS INTERVENÇÕES EM DIFERENTES CONTEXTOS}

No que tange aos contextos onde a reflexão deste artigo pode chegar, as implicações são infinitas. Nas políticas sociais setoriais como educação, saúde, assistência social e segurança pública, podemos mencionar, no mínimo, dois aspectos. O primeiro seria pensar nos impactos que estes conteúdos podem promover nos profissionais que são executores dessas políticas. Atuar na escola, na saúde, na justiça, na assistência e em outros campos requer uma atitude sensível às realidades que são desafiadoras para os próprios trabalhadores. Permitir reflexões em torno de conteúdos, prover uma discussão que nos possibilite encarar o tema como pertinente à realidade social do jovem, entendendo que sua subjetivação não se dá descontextualizada da dimensão tecnológica, são alguns dos impactos possíveis. Isso porque reverberará nos profissionais, permitindo que sejam revistos seus próprios estereótipos sobre os adolescentes e que se compreenda a importância de aprender com eles sobre suas demandas, angústias e vivências. O segundo aspecto seria o alcance para o próprio adolescente. Os jovens podem se beneficiar muito por ver políticas sociais setoriais incluírem processos dialógicos que os envolvam e sejam feitas com eles, mais do que para eles (Rossi, Marcolino, Speranza, \& Cid, 2019).

Vamos pensar, por exemplo, em algo propositivo para o contexto escolar. A ideia de trazer um filme, produzido no Brasil, pode representar um bom recurso para a promoção de conversações generativas neste cenário. "Ferrugem" nos convoca a discutir fenômenos que afetam o jovem e exibi-lo para essa comunidade pode ser uma boa estratégia para romper com silenciamentos produzidos pela falta de espaço em nossa sociedade. Ao mesmo tempo, o filme estimula a produção de sentidos para os educadores e demais profissionais, convocando também as suas representações construídas e novos processos de significação.

Para o jovem, falar de si é desafio, mas se expor para tratar a situação de uma personagem pode ser mais confortável. Daí a provocação positiva que filmes e séries promovem. $\mathrm{O}$ 
jovem não se recusa a compartilhar quando percebe o interesse do adulto por seu mundo e por sua realidade. Trazer a temática do sexting e cyberbullying por meio de um filme nacional pode ser oportuno para iniciar um diálogo de muitas vozes. Materiais disponíveis na mídia, como séries e filmes que abordam conteúdos da vivência juvenil, são recursos muito úteis na discussão de temáticas difíceis de serem acessadas. Recentemente, séries com assuntos como automutilação e suicídio foram exibidas e as escolas e famílias que oportunizaram o debate se impressionaram com significações, interpretações e argumentos dos jovens, revelando inúmeras situações semelhantes presentes em seu dia a dia.

No cenário da clínica, psicoterapeutas que atendem adolescentes preocupam-se com as narrativas que evidenciam elementos virtuais naturalizados no contexto do jovem, mas que apresentam descompasso com a compreensão de riscos vividos pelos adolescentes em suas relações. Assim como a personagem do filme, a exposição em si não é percebida como risco, mas ganha grande proporção após o vazamento de imagens.

As psicoterapias que são baseadas no construcionismo social se mostram receptivas à compreensão do cenário social no qual emergem os fenômenos dos relacionamentos virtuais e seus impactos. De acordo com Rasera e Japur (2004), as práticas terapêuticas apoiadas nesse construto trazem ênfases no significado, no processo de coconstrução, no relacionamento, na ação, na atenção às potencialidades, na polivocalidade, entre outros. Dessa forma, a decisão por uma prática psicoterápica colaborativa, por exemplo, favorece que o discurso adolescente seja ouvido e respeitado. Ao adotar uma postura de não saber, defendida por Anderson (2009), o diálogo com os adolescentes, estabelecido em terapia, permite que significados sejam criados por meio da interação das pessoas. Conforme sugere a autora, o trabalho terapêutico de "fazer com" propicia o engajamento de parceiros conversacionais que se envolvem numa investigação mútua ou compartilhada. Os entendimentos que se estabelecem de forma conjunta não são estáticos: podem ser reinterpretados, esclarecidos, revisados e criados. No campo da violência de gênero e dos impactos que o sexting e do cyberbullying promovem, é muito importante a abertura às novidades que emergem e que geram possibilidades para pensamentos, sentimentos, emoções, expressões e ações.

De acordo com Mc Namee (2018), há o perigo clínico do discurso da patologização, que tira o foco da pessoa que sofre e que pode promover a deterioração dos laços vinculares. O conceito de presença radical do terapeuta cabe aqui como uma importante contribuição de Mc Namee (2018) para apontar que essa postura requer curiosidade, responsividade e desejo de entender, além do que parece ser "óbvio", o que certamente será um diferencial terapêutico para quem o sexting e o cyberbullying possam ter impactado.

Independente do contexto nos quais o tema que abordamos aqui seja trabalhado, é útil mencionar que já se observam movimentos de isolar o fenômeno do consumo da internet como uma patologia do jovem. Tal categorização pode ser muito prejudicial, uma vez que a visão pós-moderna se opõe a diagnósticos essencialistas e intrassubjetivos, por excluir a leitura contextualizada das 
realidades que envolvem os indivíduos, a família e os sistemas nos quais estão inseridos (Mc Namee, 2018; Grandesso, 2011). Os diagnósticos de dependência da internet atribuídos ao adolescente podem reforçar estereótipos presentes na cultura que já os distanciam de interações isentas de julgamento.

\section{CONSIDERAÇÕES FINAIS}

O filme Ferrugem expõe um fenômeno complexo e nos convoca a reflexões, a posicionamentos e a ações para intervir nessa realidade. Trata-se de uma atuação que pode ser feita por profissionais da comunidade escolar e de saúde, por famílias e por amigos a partir de suas diferentes percepções. Embora o filme seja um recorte de um público de determinada classe social, há como expandir suas reflexões para as mensagens explícitas ou não, relativas à violência de gênero e às práticas de sexting e cyberbullying que devem ser consideradas alvos de nossa intervenção. Faz-se necessário descortinar esses fenômenos e dar visibilidade aos problemas e às ações, investindo em diálogo com os adolescentes cujas subjetividades foram construídas à luz da tecnologia, mas que ainda não conseguiram substitutos para uma comunicação que lhes permita revelar a riqueza e complexidade de seu mundo interno. Espera-se que este texto seja uma contribuição ao instruir interessados na temática e também convidá-los a desenvolver formas criativas de intervenção, em que as demandas dos jovens sejam consideradas de forma multidimensional. Além disso, este artigo representa um ponto de partida para estudos nacionais, tendo em vista a necessidade de investimentos teóricos no campo da prevenção de riscos no público jovem.

\section{REFERÊNCIAS}

Abreu, K., Lima, M. A., Kohlrausch, E., \& Soares, J. (2010). Comportamento suicida: fatores de risco e intervenções preventivas. Revista Eletrônica de Enfermagem, 12(1), 195-200.

Agatston, P. W., Kowalski, R., \& Limber, S. (2007). Students' perspectives on cyber bullying. Journal of Adolescent Health, 41(6), 59-60.

Albury, K., Crawford, Ku, Byron, P, \& Mathews, B. (2013). Young people and sexting in Australia. Ethics, Representation, and the Law. University of New South Wales, Australia.

Anderson, H. (2009). Uma postura filosófica: a posição, o conhecimento e a responsabilidade do terapeuta. In Conversação, linguagem e possibilidades: um enfoque pós-moderno da terapia (pp. 26-38). São Paulo: Roca. Araújo, E. M. \& Figueiredo, P. P. V. (2017). Vulnerability of children and adolescents in the use of social networks and parental mediation. Pesquisas e Práticas Psicossociais, 12(4), 1-20.

Bannink, $\mathbf{R}_{\text {s, Broeren, }} \boldsymbol{S}_{\text {s, }}$ van de LooiJ-Jansen, P. M., de Waart, F. G., \& Raat, H. (2014). Cyber and traditional bullying victimization as a risk factor for mental health problems and suicidal ideation in adolescents. PLoS One, 9(4), 94026.

Braga, L. L. \& Dell’Aglio, D. D. (2013). Suicídio na adolescência: fatores de risco, depressão e gênero. Contextos Clínicos, 6(1), 2-14.

Cardoso, A. T., Falcke, D., \& Mosmann, C. P. (2019). Sexting na adolescência: percepções dos pais. Ciências Psicológicas, 13(1), 19-31.

Carter, B. \& McGoldrick, M. (2001). As mudanças no ciclo de vida familiar: uma estrutura para a terapia fami-

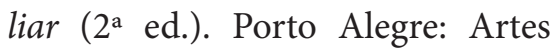
Médicas. 
Cerqueira-Santos, E., Melo Neto, 0. C., \& Koller, S. H. (2014). Adolescentes e adolescências. In L. F. Habigzang, E. Diniz, \& S. H. Koller (Eds.), Trabalhando com adolescentes: Teoria e intervenção psicológica (pp. 17-29). Porto Alegre: Artmed.

Drouin, M., Ross, J., \& Tobin, E. (2015). Sexting: A new, digital vehicle for intimate partner aggression? Computers in Human Behavior, 50, 197 204. doi: 10.1016/j.chb.2015.04.001. Drouin, M., Vogel, K. N., Surbey, A., \& Stills, J. R. (2013). Let's talk about sexting, baby: Computer-mediated sexual behaviors among young adults. Computers in Human Behavior, 29, 25-30. doi: 10.1016/j. chb.2012.12.030.

Gong, L. \& Hoffman, A. (2012) Sexting and slut-shaming: why prosecution of teen self-sexters harms women. Georgetown Journal of Gender and the Law, 13(2), 577-669.

Grandesso, M. A. (2011). Diagnóstico e terapia familiar: considerações a partir de uma epistemologia pós-moderna. In R. Payá (Org.), Intercâmbios das psicoterapias (pp. 475486). São Paulo: Roca.

Grov, C., Gillespie, B. J., Royce, T., \& Lever, J. (2011). Perceived consequences of casual online sexual activities on heterosexual relationships: a U.S. Online survey. Archives of Sexual Behavior, 40(2), 429-39.

Hasinoff, A. A. (2017). Sexting and Privacy Violations: A Case Study of Sympathy and Blame. International Journal of Cyber Criminology, 11(2), 202-217.

Juvonen, J., \& Gross, E. F. (2008). Extending the school grounds? Bullying Experiences in Cyberspace. Journal of School Health, 78(9), 496-505.

Kokkevi, A.s Rotsika, V.s Arapaki, A.s \& Richardson, C. (2010). Changes in associations between psychoso- cial factors and suicide attempts by adolescents in Greece from 1984 to 2007. European Journal of Public Health, 8(2), 1-5.

Korenis, P. \& Billick, S. B. (2014). Forensic Implications: Adolescent Sexting and Cyberbullying. The Psychiatric Quarterly, 85(1), 97-101. doi: 10.1007/s11126-013-9277-z.

Lee, M. \& Crofts, T. (2015). Gender, pressure, coercion and pleasure: untangling motivations for sexting between young people. The British Journal of Criminology, 55(3), 454473. doi: 10.1093/bjc/azu075.

Lerner, R. M. (2018). Character development among youth: Linking lives in time and place. International Journal of Behavioral Development, 42(2), 267-277.

McNamee S. \& Gergen K. (1999). Relational responsibility: resources for sustainable dialogue. California: Sage.

McNamee S. (2018). Profissionais como pessoas: encontros dialógicos para a transformação. In, M. A. Grandesso (Org.), Colaboração e Diálogo: aportes teóricos e possibilidades práticas (pp. 75-95). Curitiba: CRV.

Mejía-Soto, G. (2014). Sexting: una modalidad cada vez más extendida de violencia sexual entre jóvenes. Perinatología Reproducción Humana, 28(4), 217-221.

Mitchell, K. J., Finkelhor, D., Jones, L. M., \& Wolak, J. (2012). Prevalence and Characteristics of Youth Sexting: A National Study. Pediatrics, 129(1), 13-20. doi: 10.1542/ peds.2011-1730.

Narvaz, M. G. \& Koller, S. H. (2006). Mulheres vítimas de violência doméstica: compreendendo subjetividades assujeitadas. PSICO, 37(1), 7 -13.

Polonia, A. C. \& Dessen, M. A. (2005). Em busca de uma compreensão das relações entre família e escola. Psicologia Escolar e Educacional, 9(2), 303- 312. 
Pratta, E. M. M. \& Santos, M. A. (2007). Família e adolescência: a influência do contexto familiar no desenvolvimento psicológico de seus membros. Psicologia em Estudo, 12(2), 247-256.

Rasera, E. \& Japur, M. (2004). Desafios da aproximação do construcionismo social ao campo da psicoterapia. Estudos de Psicologia, 9(3), 431-439.

Ross, J. M., Drouin, M., \& Coupe, A. (2019). Sexting coercion as a component of intimate partner polyvictmization. Journal of Interpersonal Violence, 34(11), 2269-2291. doi: 10.1177/0886260516660300

Rossi, L. M., Marcolino, T. Q., Speranza, M., \& Cid, M. F. B. (2019). Crise e saúde mental na adolescência: a história sob a ótica de quem vive. Cadernos de Saúde Pública, 35(3), $1-12$.

Safernet. (2018). As principais violações para as quais os internautas brasileiros pedem ajuda. https:// helpline.org.br/indicadores/.

Safernet. (2019). As principais violações para as quais os internautas brasileiros pedem ajuda. https:// helpline.org.br/indicadores/.

Schiavi, A. \& Lorentz, M. (2016). Sites de Redes Sociais na Contemporaneidade: Percepções dos Usuários Sobre Emoções, Vivências e Relações. Revista de Psicologia da IMED, 8(2), 133- 141.

Senna, S. R. C. M. \& Dessen, M. A. (2012). Contribuições das teorias do desenvolvimento humano para a concepção contemporânea da adolescência. Psicologia: Teoria \& Pesquisa, 28(1), 101-108.

Souza, A. A. C. \& Cintra, R. B. (2018). Conflitos éticos e limitações do atendimento médico à mulher vítima de violência de gênero. Revista Bioética, 26(1), 77-86.

Swim, J. K. \& Hayes, L. L. (2009). Sexism. In T. D. Nelson (Ed.), Handbook of prejudice, stereotyping, and discrimination (pp. 407-430). New York: Psychology Press Taylor \& Francis Group. doi: 10.4324/9781841697772.

Wagner, A., Carpenedo, C., Melo, L. P.s \& Silveira, P. G. (2005). Estratégias de Comunicação Familiar: A Perspectiva dos Filhos Adolescentes. Psicologia: Reflexão e Crítica, 18(2), 277-282.

Walker, S., Sanci, L., \& Temple-Smith, M. (2013). Sexting: young women's and men's views on its nature and origins. Journal of Adolescent Health, 52(6): 697-701.

Wendt, G. W. \& Lisboa, C. S. (2013). Agressão entre pares no espaço virtual: definições, impactos e desafios do cyberbullying. Psicologia Clínica, 25(1), 73-87.

Ybarra, M. L. \& Mitchell, K. J. (2014). "Sexting" and Its Relation to Sexual Activity and Sexual Risk Behavior in a National Survey of Adolescents. Journal of Adolescent Health, 55(6), 757-764. doi: 10.1016/j. jadohealth.2014.07.012. 


\section{SILVIA RENATA LORDELLO}

É psicóloga e pedagoga pela Universidade de Brasília, docente no Departamento de Psicologia Clínica da Universidade de Brasília e Programa de Pós-Graduação em Psicologia Clínica gênero, sexting cyberbullying no filme ferrugem

e Cultura na Universidade de Brasília.

E-mail: srmlordello@gmail.com

\section{LARA SOUZA}

É psicóloga e bacharela formada pela Universidade de Brasília. Mestranda no Programa de Pós-Graduação em Psicologia Clínica e Cultura. Pós-Graduada em Terapia Analítico-Comportamental Infantil pelo Instituto Brasiliense de Análise do Comportamento. E-mail: larasouzafeitosa@gmail.com

\section{LETÍCIA DE AMORIM MOTA COELHO}

É psicóloga, bacharela e licenciada pela Universidade de Brasília. Residente do Programa de Saúde Mental Adulto da Escola de Ciências da Saúde, vinculada à Secretaria da Saúde do Distrito Federal.

E-mail: leticiaamorim.mota@gmail.com 